\title{
Fitting ARIMA model for volatility insurance time series data
}

\author{
S. Al Wadi ${ }^{1}$, Ola Basbous ${ }^{2}$ \\ 1. Department of Finance, Faculty of Business, The University of Jordan, Jordan. \\ E-mail: Sadam_alwadi@yahoo.co.uk \\ 2._MBA researcher, E-mail: ola-alsham@hotmail.com
}

\begin{abstract}
The volatility of stock market data have contributed an essential section in risk study and it is very serious problem especially in emerging markets. Previously it is measured by standard deviation of the return. Therefore, in this article the volatility data will be predicted based on Autoregressive Integrated Moving Average model (ARIMA) using insurance stock market data from Amman Stock Exchange (ASE) from January 2019 to December 2019. As a result this article shows that the ARIMA model has significant results for short-term prediction. Therefore, These results will be helpful for the investments.
\end{abstract}

Keywords: ARIMA model, forecasting, Insurance Sector

DOI: $10.7176 / \mathrm{EJBM} / 11-36-13$

Publication date: December $31^{\text {st }} 2019$

\section{Introduction}

volatility is one of the concerning points for many researchers in financial institutions specially in emerging markets. Therefore, many researchers have focus in the volatility field such as forecasting, detecting and modeling volatility. Recently, many models of volatility models have been recommend in the in order to make testing the fundamental trade-off between return and risk of financial assets such as Generalized Autoregressive Conditional Heteroskedasticity (GARCH) model is the first and famous model in application of the volatility. This model is usually implemented for modeling and predicting volatility for the stock market data for more details refer to (Babu \& Reddy, 2015). As we stated before, numerous researchers have concentrated on the volatility data since all the stock market data are highly volatile. Consequently, the data trend and accuracy supplies can be met simultaneously (Babu \& Reddy, 2015). Therefore, this reason encourage the researchers to improve many methods for modeling for forecasting volatility data such as (Bentes, 2015) discuss the GARCH model in recitation the gold volatility performance. (Joukar \& Nahmens, 2015) implemented ARCH and GARCH models to determine the persistency volatilities, for more details about the volatility data in content of modeling and predicting refer to (Abounoori, et al., 2016; Byun , 2016; Bollerslev et al., 2016). The mathematical definition of volatility can be defined (Al Wadi, 2010). Generally volatility data is very hard in decomposition and forecasting because the data are non-stationary and non-linear with high heteroscedasticity [pai and lin, 2005; Wang, et. al., 2012; Wei, 2013, Tabachnick and Fidell, 2001]. The plan of the investors is to improve their profits less risk. This idea force the academics to improve many predicting models such as artificial neural network, hybrid models and ARIMA models for more details refer to [Mitra, 2009, Atsalakis and Kimon, 2009, Mohamed, 2010, Tabachnick and Fidell, 2001], Atsalakis, 2011; Tabachnick and Fidell, 2001]. ARIMA model is an old-style model with extensively application in stock market data application [Wang, 2012, Awajan, et. al., 2017, Awajan, et. al., 2017; Al-Khazaleh,et al., 2015; Awajan, et. al., 2017; Al Wadi, 2013 ].

Hundred or maybe thousands of articles have published using ARIMA model in all of the fields of sciences. Therefore, in order to highlight the gap and the differences between this work and previous works the a critically review should be presented, Many academics have been developing predicting models such as exponential method, regression model, GARCH approaches and others. However, only some related works that has used ARIMA model in predicting stock market data for more details refer to [Javier, et. al., 2003;; Khasel, et. al., 2009; Lee and Ho, 2011; Khashei, et. al., 2012; Wang, 2011; Meyler, et. al., 1998]. Whereas, rarely to find any article that utilize Amman Stock Exchange using ARIMA model in forecasting such as (Al Wadi, 2015). Especially the volatility of stock market data for the recent year.

This research is organized as: Section 2 is the mathematical model. section 3 presents the results and discussion. Finally, in section 4 is the conclusion. 


\section{Autoregressive Integrated Moving-Average Model (ARIMA (p,d,q))}

The auto-regressive moving average is signified by (ARMA) model is implemented for stationary data only, it contains three combination models [Awajan, et. al., 2017]. An addition of the ordinary ARMA model is the autoregressive integrated moving-average model $(\operatorname{ARIMA}(\mathrm{p}, \mathrm{d}, \mathrm{q}))$ given by :

$$
\phi_{\mathrm{p}}(\mathrm{B})(1-\mathrm{B})^{\mathrm{d}} \mathrm{Y}_{\mathrm{t}}=\grave{\mathrm{e}}_{0}+\grave{\mathrm{e}}_{\mathrm{q}}(\mathrm{B}) \mathrm{e}_{\mathrm{t}}
$$

Where $\mathrm{p}, \mathrm{d}$ and $\mathrm{q}$ denote orders of auto-regression, integration (differencing) and moving average, respectively. When $d=0$, the ARIMA model reduces to the ordinary ARMA model [Awajan, et. al., 2017].

\section{Result and discussion}

The MINTAB software is implemented to produce the results. The daily insurance data from ASE for a specific period of time has been selected as the statistical population, about 250 observations were accumulated. There are many ARIMA model can be recognized for one column of dataset based on using different values of p,d and q. Therefore, the fitted ARIMA model which has less MSE (Mean Square Error). The following Table will shows all the possible fitted ARIMA models with its MSE.

Table 1 shows all the possible ARIMA models with its RMSE

\begin{tabular}{|l|l|l|l|l|l|}
\hline ARIMA & MSE & ARIMA & MSE & ARIMA & MSE \\
\hline$(0,0,0)$ & $\mathrm{N}$ & $(0,2,0)$ & $\mathrm{N}$ & $(1,1,2)$ & $\mathrm{N}$ \\
\hline$(0,0,1)$ & 0.00000156 & $(0,2,2)$ & $\mathrm{N}$ & $(1,2,0)$ & $\mathrm{N}$ \\
\hline$(0,0,2)$ & 0.000001433 & $(1,0,0)$ & 0.000001452 & $(1,2,1)$ & $\mathrm{N}$ \\
\hline$(0,1,0)$ & $\mathrm{N}$ & $(1,0,1)$ & 0.000001307 & $(1,2,2)$ & $\mathrm{N}$ \\
\hline$(0,2,0)$ & $\mathrm{N}$ & $(\mathbf{1}, \mathbf{0}, \mathbf{2})$ & $\mathbf{0 . 0 0 0 0 0 1 2 9 7}$ & $(2,0,0)$ & $\mathrm{N}$ \\
\hline$(0,1,1)$ & 0.000001358 & $(1,1,0)$ & 0.000001476 & $(2,0,1)$ & $\mathrm{N}$ \\
\hline$(0,1,2)$ & 0.000001359 & $(1,1,1)$ & $\mathrm{N}$ & $(2,0,2)$ & $\mathrm{N}$ \\
\hline$(2,1,0)$ & 0.000001401 & $(2,1,2)$ & $\mathrm{N}$ & $(2,2,1)$ & $\mathrm{N}$ \\
\hline$(2,1,1)$ & $\mathrm{N}$ & $(2,2,0)$ & $\mathrm{N}$ & $(2,2,2)$ & $\mathrm{N}$ \\
\hline
\end{tabular}

Based on Table 1 the researchers notes that:

1) The values of $\mathrm{p}, \mathrm{d}$ and $\mathrm{q}$ are between 0 and 2 only since these values impossible to be in the minus also theses values should not be more than 2 since the estimation of the parameters will be worthless.

2) After the dataset is implemented using the software then ARIMA $(1,0,2)$ was found the best with MSE= 0.000001297

3) In some cases ARIMA model is not fitted which means that the estimation of the dataset cannot be done then it should be ignored.

\section{Conclusion}

This paper showed a significant model that carries a good predicting model of the new high technology procedure. Subsequently, collecting sufficient data to predict insurance stock market data, an ARIMA model are applied over the dataset performed to improve the prediction. Around 250 observations were collected to appliance the forecasts of this and the best ARIMA model were selected based on the most famous criteria which is MSE (Mean Square Error). The method was limited to a short term forecasting and it is not useful for long term. Future research in this topic includes other forecast horizons stock market data such as industrial data also the future values can be found using the suggested model. 


\section{References}

Abounoori, E., Elmi, Z., \&Nademic, Y. (2016), Forecasting Tehran stock exchange volatility; Markov switching GARCH approach, Physica A: Statistical Mechanics and its Applications, 445, 264-282.

Al-Khazaleh, Ahmad MH, S. Al Wadi, and Faisal Ababneh. ( 2015) ."Wavelet transform asymmetric winsorized mean in detecting outlier values". Far East Journal of Mathematical Sciences . 96.3: 339-351.

Al Wadi, S., Abdulkareem Hamarsheh, and Hazem Alwadi. (2013). "Maximum overlapping discrete wavelet transform in forecasting banking sector." Applied Mathematical Sciences. 7.80 : 3995-4002.

Alwadi, S., (2015). Forecasting Short Term Financial Data. European Scientific Journal 11, No.25. 251 -255.

Al Wadi, S. (2017). Improving volatility risk forecasting accuracy in industry sector. International Journal of Mathematics and Mathematical Sciences, 2017.

Al Wadi, S., Ismail, M. T., \& Abdul Kari, S. A. (2011). Discovering Structure breaks in Amman stocks market. Journal of Applied Sciences, 11, 1273-1278.

Alsaraireh, A. A., Almasarweh, M., Alnawaiseh, M. B., Al Wadi, S., \& Bhama, V. (2018).The Effect of methods of operation research in obtaining the best result in the, Italian journal of pure and applied mathematics, (40),501-509.

Atsalakis, G. S., \& Valavanis, K. P. (2009). Forecasting stock market short-term trends using a neuro-fuzzy based methodology. Expert systems with Applications, 36(7), 10696-10707.

Awajan, Ahmad M., Mohd Tahir Ismail, \& Al Wadi. (2017). "A Hybrid Approach EMD-MA For Short-Term Forecasting Of Daily Stock Market Time Series Data. Journal Of Internet Banking And Commerce 22.1.

Awajan, A. M., Ismail, M. T., \& Al Wadi, S. (2017). A hybrid emd-ma for forecasting stock market index. Italian Journal of Pure and Applied Mathematics, 38(1), 1-20.

Awajan, A. M., Ismail, M. T., \& Wadi, S. A. (2017). Forecasting time series using EMD-HW bagging. International Journal of Statistics \& Economics ${ }^{\mathrm{TM}}$, 18(3), 9-21.

Bollerslev, T., Patton, A., \& Quaedvlieg, R., (2016), Exploiting the errors: A simple approach for improved volatility forecasting, Journal of Econometrics, 192, 1- 18.

Babu, C. N., \& Reddy, B. E. (2015). Prediction of selected Indian stock using a partitioning-interpolation based ARIMA-GARCH model. Applied Computing and Informatics, 11(2), 130-143.

Joukar, A., \& Nahmens, I. (2015). Volatility forecast of construction cost index using general autoregressive conditional heteroskedastic method. Journal of construction engineering and management, 142(1), 04015051 .

Javier, C., Rosario, E., Francisco, J. N., \& Antonio, J. C. (2003). "ARIMA models to predict next electricity price". IEEE Transactions on Power Systems, 18(3), 1014-1020.

Khashei, M., Bijari, M., \& Ardali, G. A. R. (2009). Improvement of auto-regressive integrated moving average models using fuzzy logic and artificial neural networks (ANNs). Neurocomputing, 72(4-6), 956-967.

Khashei, M., Bijari, M., \& Ardali, G. A. R. (2012). Hybridization of autoregressive integrated moving average (ARIMA) with probabilistic neural networks (PNNs). Computers \& Industrial Engineering, 63(1), 37-45.

Lee, C. M., \& Ko, C. N. (2011). "Short-term load forecasting using lifting scheme and ARIMA models". Expert Systems with Applications, 38(5), 5902-5911.

Meyler, A., Kenny G., and Quinn, T., (1998). "Forecasting Irish Inflation using ARIMA Models", Central Bank of Ireland Research Department. Technical Paper.

Mitra, S. K. (2009). Optimal combination of trading rules using neural networks. International business research, 2(1), 86-99.

Mostafa, M. M. (2010). Forecasting stock exchange movements using neural networks: Empirical evidence from Kuwait. Expert Systems with Applications, 37(9), 6302-6309.

Pai, P. F., \& Lin, C. S. (2005). A hybrid ARIMA and support vector machines model in stock price 
forecasting. Omega, 33(6), 497-505.

Tabachnick \& Fidell, (2001), "Using multivariate statistics”, 4th ed., Person Education Company, USA.

Wang, C., (2011). "A comparison study of between fuzzy time series model and ARIMA model for forecasting Taiwan Export”, Expert System with Applications, 38, (8), 9296-9304.

Wang, J. J., Wang, J. Z., Zhang, Z. G., \& Guo, S. P. (2012). Stock index forecasting based on a hybrid model. Omega, 40(6), 758-766.

Wei, L.Y. (2013)., "A hybrid model based on ANFIS and adaptive expectation genetic algorithm to forecast TAIEX”, Economic Modelling, 33, 893-899. 